\title{
Optical ammonia sensors based on fluorescent aza-BODIPY dyes- a flexible toolbox
}

\author{
Maximilian Maierhofer ${ }^{1} \cdot$ Veronika Rieger $^{1} \cdot$ Torsten Mayr $^{1}$
}

Received: 13 July 2020 / Revised: 7 August 2020 / Accepted: 17 August 2020 / Published online: 24 August 2020

(C) The Author(s) 2020

\begin{abstract}
We present three types of optical ammonia sensors suitable for environmental, bioprocess, and reaction monitoring. A respective fluorescent $\mathrm{BF}_{2}$-chelated tetraarylazadipyrromethene dye (aza-BODIPYs) is physically entrapped in a polyurethane hydrogel (HydroMed D4) forming an emulsion system with vinyl-terminated polydimethylsiloxane (PDMS). The analyte-sensitive layer is covered by a hydrophobic membrane which excludes hydrophilic substances. Three different protection layers are tested, whereby the Teflon and the hydrophobic PES layers outperform a PDMS/TiO 2 layer. Response times within their dynamic range of $15 \mathrm{~s}$ can be achieved, whereas the $\mathrm{PDMS} / \mathrm{TiO}_{2}$-covered sensor requires at least $390 \mathrm{~s}$. The three sensors entail the following concentration areas: first sensor $3 \mu \mathrm{g} \mathrm{L}^{-1}-3 \mathrm{mg} \mathrm{L}^{-1}$ (LOD $0.23 \mu \mathrm{g} \mathrm{L}^{-1}$ ), second sensor $0.1-30 \mathrm{mg} \mathrm{L}^{-1}$ (LOD $28 \mu \mathrm{g} \mathrm{L}^{-1}$ ), and third sensor $3 \mathrm{mg} \mathrm{L}^{-1}-1 \mathrm{~g} \mathrm{~L}^{-1}$ (LOD $0.51 \mathrm{mg} \mathrm{L}^{-1}$ ). Readout is performed with a commercially available phase fluorimeter combined with optical fibers. Dual-lifetime referencing (DLR) is used as referencing method and Egyptian blue acts as an inert reference material. No cross-sensitivity to $\mathrm{pH}$ changes can be detected.
\end{abstract}

Keywords $\mathrm{pH}$ indicator $\cdot$ Phase fluorimetry $\cdot$ Dual-lifetime referencing $\cdot$ Bioprocessing $\cdot$ Online monitoring $\cdot$ Chemical sensor

\section{Introduction}

Ammonia is an ubiquitous compound. It is used by humans in industrial fertilizers and refrigerants. Furthermore, it is produced by animals as an excretion product as well as a product in amino acid degradation and waste decomposition [1]. Since there are many origins for ammonia on our planet, it can be found in different habitats, such as river [2] and seawater [3], the atmosphere [4], and soil. As ammonia is toxic for most animals and humans even in trace concentrations, it is an analyte of high interest in environmental monitoring [5]. Due to rising earth population and dealing with the problem of overfishing in the seas, fish farming is gaining more attention. Thereby, ammonia is a crucial parameter which has to be monitored carefully [6]. Even to many microorganisms,

Electronic supplementary material The online version of this article (https://doi.org/10.1007/s00216-020-02891-3) contains supplementary material, which is available to authorized users.

Torsten Mayr

torsten.mayr@tugraz.at

1 Institute of Analytical Chemistry and Food Chemistry, Graz University of Technology, Stremayrgasse 9/2, 8010 Graz, Austria ammonia is a toxic compound. Continuous mammalian cell lines (CCLs), which are important hosts for the production of biological pharmaceuticals, generate ammonia during the cell metabolism. This is due to the lack of energy in form of ATP (adenosine-5'-triphosphate) [7, 8]. To close this gap, these cells consume glutamine to produce $\alpha$-ketoglutarate, which is further degraded in the mitochondria and as a second product poising ammonia [9]. Ammonia inhibits cell growth and further yields to cell death [10].

Many different methods for the determination of dissolved ammonia have been developed. Thereby, IR measurements [11] as well as electrochemical approaches like potentiometric electrodes [12] and conductometric [13], photoacoustic [14, 15] photothermal [16], and amperometric methods [2] are worth mentioning. In analytical routine analysis, colorimetric methods based on Berthelot's [17, 18] and Nessler's reaction [19] are well established. However, these methods either consume analyte, convert the analyte chemically into another species, or require expensive and bulky instrumentation. Others need sample preparation making them less suitable for fieldtrips or online monitoring. The colorimetric methods lack a slow chemical reaction kinetic and require trained personal in the sample preparation step. Since we wanted to develop a low-cost sensor which is suitable for online monitoring, we 
have chosen a different sensing technique: Within the concept of optical sensing, different indicator dye classes suitable for ammonia sensing have been already published. Xanthene dyes [20-24], coumarin derivatives [25-27], $\mathrm{Ru}$ (II) polypyridyl dyes [28], and triphenylmethane dyes [29, 30] have been investigated intensively. Most dyes of these classes show poor photostability/long-term stability and are not sensitive enough for trace measurements. This fact makes them unsuitable for environmental monitoring.

We present an optical ammonia sensor based on $\mathrm{BF}_{2}$-chelated tetraarylazadipyrromethene dyes (aza-BODIPY). These show high photostability [31], are excitable with low-cost red LEDs $(\sim 620 \mathrm{~nm})$, and emit in the near infrared region of the spectrum $(650-750 \mathrm{~nm})$ [32]. Within this region, autofluorescence of biomolecules is decreased yielding in less background scattering. This decrease makes the sensor more sensitive. Our sensing system relies on an acid-base concept. Here, the analyte in its gaseous form diffuses through a porous, hydrophobic membrane into the sensing layer. It deprotonates the indicator dye inducing fluorescence quenching [33]. With varying $\mathrm{p} K_{\mathrm{a}}$ of the dye's hydroxyl group, we can tune the sensitivity of our optical ammonia sensor offering different applications in the broad field of analytical ammonia detection. The readout is performed via a miniaturized phase fluorimeter which is combined with optical fibers using dual-lifetime referencing (DLR) as the determination method.

\section{Material and methods}

The three aza-BODIPY dyes $\mathrm{Cl}_{2} \mathrm{OHC}_{12}$, apparent $\mathrm{p} K_{\mathrm{a}}$ value of 3.93, (4-(7-(3,5-dichloro-4-hydroxyphenyl)-5,5-difluoro1,9-diphenyl-5H-5 $\lambda^{4}, 6 \lambda^{4}$-dipyrrolo[ $\left[1,2-c: 2^{\prime}, 1^{\prime}\right.$ f] $[1,3,5,2]$ triazaborinin-3-yl)- $N$-dodecylbenzamide); $\mathrm{ClOHC}_{12}$, apparent $\mathrm{p} K_{\mathrm{a}}$ value of 7.01, (4-(7-(3-chloro-4hydroxyphenyl)-5,5-difluoro-1,9-diphenyl-5H-5 $\lambda^{4}, 6 \lambda^{4}$ dipyrrolo[1,2-c:2', $1^{\prime}$-f $][1,3,5,2]$ triazaborinin-3-yl)- $N$ dodecylbenzamide); and OHBut, apparent $\mathrm{p} K_{\mathrm{a}}$ value of 8.90 , (4-(7-(4-butoxyphenyl)-5,5-difluoro-1,9-diphenyl-5H$4 \lambda^{4}, 5 \lambda^{4}$-dipyrrolo[1,2-c:2', $1^{\prime}$-f $][1,3,5,2]$ triazaborinin-3yl)phenol) were synthesized in-house as described previously. The corresponding structural confirmation of these dyes is already published in literature [34]. Silanized Egyptian blue used as microcrystalline powder was prepared as described in the literature [35]. Sodium dihydrogen phosphate monohydrate was bought from Carl Roth GmbH (https:// www.carlroth.com/de/de, Karlsruhe, Germany). The polyurethane hydrogel, HydroMed D4, was purchased from AdvanSource biomaterials (www.advbiomaterials.com, Wilmington, USA). 4-Dodecylbenzene sulfonic acid (DBSA), platinum(0)-1,3-divinyl-1,1,3,3-tetramethyldisiloxane complex solution $(\operatorname{Pt}(0)$-cat), and ammonium chloride were purchased from Sigma Aldrich (https://www.sigmaaldrich.com/austria.html, St. Louis, USA). Fluoropore ${ }^{\mathrm{TM}}$ membrane PTFE $(0.45 \mu \mathrm{m}$ pore size, $50 \mu \mathrm{m}$ thickness, Teflon layer) was bought from Merck Millipore Ltd. (http://www.merckmillipore.com/AT/de, Cork, Ireland). The superphobic PES $0.2 \mu \mathrm{m}$ membrane (no data for the layer thickness available, PES layer) was a project contribution from EMD Millipore Corporation (Billerica, MA, USA). The support, poly(ethylene naphthalate) (PEN) foil Teonex, was from Pütz (https://www.puetz-folien.com/ index.php/de/, Tanusstein, Germany). Poly(dimethylsiloxane), vinyldimethylsiloxy terminated (viscosity 1000 cSt., PDMS), $(25-35 \%$ methylhydrosiloxane)-dimethylsiloxane copolymer (viscosity 25-35 cSt., copolymer) and 1,3,5,7-tetravinyl1,3,5,7-tetramethylcyclotetrasiloxane (restrainer) were purchased from abcr GmbH (https://www.abcr.de/de/, Karlsruhe, Germany). Ultrafine titan oxide $\left(\mathrm{TiO}_{2}\right) \mathrm{P} 170$ was from Kemira Oyj (https://www.kemira.com/; Helsinki, Finland). All chemicals and substances were used without additional purification.

Fluorescence spectra of the dyes were recorded with a Fluorolog3spectrofluorimeter (Horiba J. Y., www.horiba. com) equipped with a NIR-sensitive photomultiplier R2658 from Hamamatsu (300-1050 nm). Measurements of the DLRreferenced sensors were performed with a commercially available Firesting $\mathrm{O}_{2}$ reader (https://www.pyroscience.com, PyroScience $\mathrm{GmbH}$, Aachen, Germany) in combination with plastic optical fibers $(\varnothing 1 \mathrm{~mm}$, length $1 \mathrm{~m}$, https://www. ratioplast.com/index.php/en/home, RatioplastOptoelectronics GmbH, Lübbecke, Germany). The following settings for the calibration measurements were used: measuring time of $10 \mathrm{~ms}$, LED intensity $100 \%$, amplification of $400 \times$, a modulation frequency of $2000 \mathrm{~Hz}$, and a measuring interval of $3 \mathrm{~s}$.

All calibrations were performed in a temperaturecontrolled glass vessel filled with aqueous phosphatebuffered solutions at a defined $\mathrm{pH}$ (see Electronic Supplementary Material (ESM) Table S1) containing different amounts of free $\mathrm{NH}_{3}$. Additionally, a temperature sensor is implemented into the setup to the respective ammonia sensor (Fig. 1a).

\section{Sensor composition and preparation}

We used an emulsion concept for our system based on earlier experiments. This has shown that the assembling yields in more stable sensors [36]. First, $0.25 \mathrm{mg}(0.5 \mathrm{w} / \mathrm{w})$ of the respective fluorescent aza-BODIPY dye is dissolved $500 \mathrm{mg}$ of a hydrogel D4 $(50 \mathrm{mg}, 10 \mathrm{w} / \mathrm{w})$ solution in $\mathrm{EtOH} / \mathrm{H}_{2} \mathrm{O}(9+1)$. Second, acid in form of nonvolatile 4-dodecylbenzene sulfonic acid (DBSA, $1.0 \mathrm{mg}, 100 \mu \mathrm{L}$ of a $10 \mathrm{mg} \mathrm{mL} \mathrm{mL}^{-1}$ solution in THF) is added to protonate the dye. All dye molecules are now in 
Fig. 1 a Calibration measurement setup, temperature-controlled double-walled glass vessel. b Fiber optic sensors $5 \mathrm{~mm}$ spots sealed with a stainless screw cap to an optical fiber. c Zoomed picture of an optical sensor

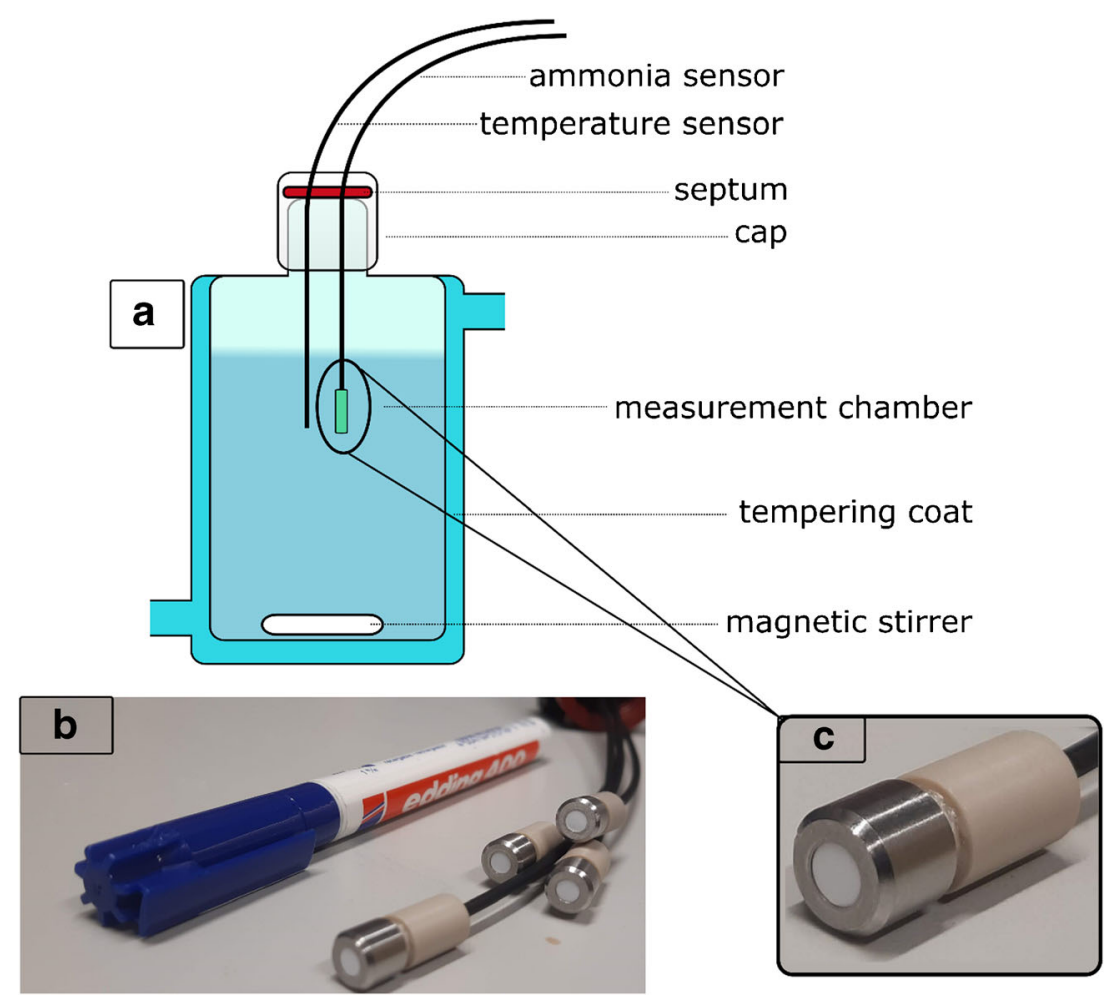

their "on-state" and show fluorescence. This ensures a better stabilization of the baseline signal which further yields into more reliable measurement signals. After adding the host material, that is vinyl-terminated polydimethylsiloxane (PDMS, $500 \mathrm{mg}$ ), the sensor "cocktail" is heated up to $100{ }^{\circ} \mathrm{C}$ to remove the solvents. Thereby, it is emulsified for $20 \mathrm{~min}$ (2000 rpm). After cooling to room temperature, (25-35\% methylhydrosiloxane)-dimethylsiloxane (copolymer, $20 \mu \mathrm{L}$ ), 1,3,5,7-tetravinyl-1,3,5,7-tetramethylcyclotetrasiloxane (restrainer, $20 \mu \mathrm{L}$ of a $10-\mathrm{mg} \mathrm{mL}^{-1}$ stock solution in cyclohexane) and silanized Egyptian blue as a reference material $(5 \mathrm{mg})$ are added to the emulsion. Before adding platinum(0)-1,3-divinyl1,1,3,3-tetra-methyldisiloxane complex solution $(\mathrm{Pt}(0)$-cat, $10 \mu \mathrm{L}$ ), the "cocktail" is emulsified at room temperature for 5 min The emulsion is knife-coated $(25 \mu \mathrm{m}$ wet film) on a dust-free PEN support $(125 \mu \mathrm{m})$. Finally, a hydrophobic layer (either a Fluoropore membrane PTFE (A1, B1, and C1) or a hydrophobic PES layer (A2, B2, and C2) is laid carefully onto the wet film. In the case of sensor B3, a mixture of PDMS and $\mathrm{TiO}_{2}$ is used as an ion barrier. A stock solution of $5 \mathrm{~g}$ PDMS, $1.0 \mathrm{~g} \mathrm{TiO}_{2}$, and $200 \mu \mathrm{L}$ copolymer in $2 \mathrm{~mL}$ cyclohexane is used. The respective amounts of restrainer and catalyst are added before knife coating ( $25 \mu \mathrm{m}$ wet film onto the sensing layer).

After $4 \mathrm{~h}$, the PDMS is polymerized and the sensor material is ready to use. Sensor spots are punched out with a stainless steel ferrule $(\varnothing 5 \mathrm{~mm})$ and fixed via a stainless steel screw cap to an optical fiber (see Fig. 1b, c). In Table 1, all sensors classified by indicator dye and ion barrier are listed.

\section{Dual-lifetime referencing}

Fluorescence intensity measurements are influenced by many factors like fluctuation of the excitation source, performance of the detector, and electronic interferences. Due to this, we have chosen a different sensing method. It is called duallifetime referencing (DLR) whereby the fluorescence intensity ratio of an analyte-sensitive dye with a short lifetime and an inert reference having a long lifetime is contributing to an overall phase shift (dphi). Therefore, both are excited simultaneously with a modulated light pulse. Further conversion of dphi into cotangent values represent a direct proportionality to the fluorescence intensity [37]. As reference, the indicator Egyptian blue was chosen due to its photochemical inert behavior and spectral compatibility to the aza-BODIPY dyes. Both indicators can be excited with a red LED, which makes

Table 1 Sensor composition listed by used dye and ion barrier

\begin{tabular}{lll}
\hline Sensor & Dye & Ion barrier \\
\hline A1 & $\mathrm{Cl}_{2} \mathrm{OHC}_{12}$ & Teflon \\
$\mathrm{A} 2$ & $\mathrm{Cl}_{2} \mathrm{OHC}_{12}$ & hydrophobic PES \\
$\mathrm{B} 1$ & $\mathrm{ClOHC}_{12}$ & Teflon \\
$\mathrm{B} 2$ & $\mathrm{ClOHC}_{12}$ & hydrophobic PES \\
$\mathrm{B} 3$ & $\mathrm{ClOHC}_{12}$ & $\mathrm{TiO}_{2} / \mathrm{PDMS}$ \\
$\mathrm{C} 1$ & $\mathrm{OHBut}_{\mathrm{C}}$ & Teflon \\
$\mathrm{C} 2$ & OHBut & Hydrophobic PES \\
\hline
\end{tabular}


them compatible with the commercially available Firesting $\mathrm{O}_{2}$ reader from Pyroscience, and emit in the NIR spectral region.

\section{Results and discussion}

\section{Choice of materials}

A common concept in sensor technology is the layer by layer concept whereby the sensing layer is knife coated on top of a support material. On top of the sensing layer, either an optical isolation or another type of protection layer (e.g., ion barrier) is built. Previous studies have shown that the layer by layer concept has no long-term stability for this application; we have chosen an emulsion concept (Fig. 2) [36]. The study by Strobl et al. has overcome the problem of poor sensor stability but did not yield into a quick sensor response. Since we wanted to build a modular toolbox for ammonia sensing suitable for a wide range of applications, we improved this sensor concept. Therefore, three aza-BODIPY dyes (different in their apparent $\mathrm{p} K_{\mathrm{a}}$ values) as indicators, a PDMS matrix as a host material, a hydrogel D4 for dye incorporation, and three different ion barriers were tested (see Table 1).

The dynamic range of the sensor is limited to the apparent $\mathrm{p} K_{\mathrm{a}}$ of the indicator dye, since this sensing principle is set upon an acid-base system (Fig. 2). The lower the $\mathrm{p} K_{\mathrm{a}}$ value, the more sensitive the sensor is and vice versa. As a basic structure, we have chosen aza-BODIPY dyes (see Fig. 3, left) due to their high photostability, spectral properties (excitable via red LED, emit in the NIR region (Fig. 3, right), good brightness), and structural diversity (see Fig. 3, left) [31]. By introducing electron-withdrawing or electron-donating groups in the two ortho-positions to the phenol group, the apparent $\mathrm{p} K_{\mathrm{a}}$, which was measured in a solution of $\mathrm{EtOH} / \mathrm{H}_{2} \mathrm{O} 1+1$, of the hydroxyl group can be varied from 3.9 up to 8.9 [34]. The fact that we can use different indicator dyes in our system yields into a broad range of possible application. On the one hand, we can build a trace sensor which is suitable for $\mathrm{NH}_{3}$ concentrations down to low micrograms per liter. These are demanded for fish farming. On the other hand, we can also monitor ammonia within biocatalytic reactions in which common concentrations up to several milligrams per liter of free $\mathrm{NH}_{3}$ can be expected. In its protonated state, the dye emits fluorescence (IndH), whereas the proton is transferred in the presence of ammonia and the fluorescence is switched off due to a photoinduced electron transfer (PET; see Fig. 2).

For a rapid sensor response, a fast diffusion of ammonia through the ion barrier and the host matrix is favorable. As host material PDMS, which acts permeation-selectively for hydrophobic species, is tested due to its outstanding high diffusion rate for ammonia [38]. To avoid interferences caused by hydrophilic species, this sensor concept requires a ion barrier on top of the sensing layer. In this study, three different materials were tested as possible ion barriers. First, the hydrophobic Teflon membrane filter is known to have a high diffusion rate for ammonia due to its highly porous structure as well as its thin layer thickness. It is therefore suitable as a protection layer. Due to its hydrophobic nature, crosssensitivity towards varying salinity is also negligible [39]. Additionally, fluoropolymers are highly resistant to biofouling which makes them suitable for measuring in environmental samples or bioreactors (see Fig. 1b, c, white $5 \mathrm{~mm}$ spot) [40]. Second, a mixture of PDMS/ $/ \mathrm{TiO}_{2}$ was knife coated on top of the sensing layer. Thereby, the PDMS works as an ion barrier and the $\mathrm{TiO}_{2}$ acts as an optical isolation. As a third material, a hydrophobic PES layer was laid on top of the wet sensing layer. This layer might be an alternative to the mechanically more fragile Teflon layer.

\section{Sensing performance and stability}

In its left part, Fig. 4 shows the sensor response of the three sensors A1, B2, and C2 whereby a decrease of the phase angle dphi correlates to an increase in the concentration of the protonated dye form. This figure also shows the reversibility of the sensors. Due to their high stability and good reversibility combined with the right proton barrier, these sensors are the best candidates for the specific application fields: A1 as sensor for fish farming or environmental monitoring (measurement range for free ammonia in the low $\mu \mathrm{g} \mathrm{L}^{-1}$ area), B2 in biocatalysis (measurement range for free ammonia up to more than $10 \mathrm{~m} \mathrm{~L} \mathrm{~L}^{-1}$ ), and $\mathrm{C} 2$ in chemical reaction monitoring (measurement range for free ammonia more than $1 \mathrm{~g} \mathrm{~L}^{-1}$ ). Figure S4 (see the ESM) shows the response curves and stability tests of the remaining sensors (A2, B1, B3, and C1).

Plotting the cot(dphi) against the $\mathrm{NH}_{3}$ concentration yields a sigmoidal curve (Fig. 5) which is further fitted by the following Boltzmann fit (1):
Fig. 2 Sensor concept: gaseous $\mathrm{NH}_{3}$ diffuses through a hydrophobic layer into the sensing layer to the dye. Thereby, it deprotonates the hydroxy group of the dye and shuts off the fluorescence

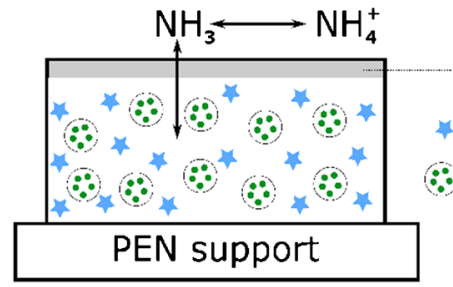

hydrophobic porous layer

* Egyptian Blue

6 indicator dye in Hydrogel D4

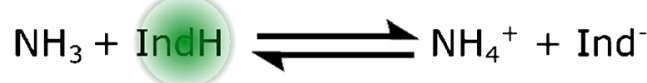


Fig. 3 Left: Molecular structure of three aza-BODIPY dyes: $\mathrm{Cl}_{2} \mathrm{OH}_{12}, \mathrm{ClOHC}_{12}$, OHBut; right: emission spectra $(\lambda$ exc $=$ $610 \mathrm{~nm}$ ) of sensor foils with either $\mathrm{Cl}_{2} \mathrm{OHC}_{12}$ (red), $\mathrm{ClOHC}_{12}$ (blue), or OHBut (black) as an indicator in the protonated state and Egyptian blue $\left(\lambda \_\max =900 \mathrm{~nm}\right)$ as a reference
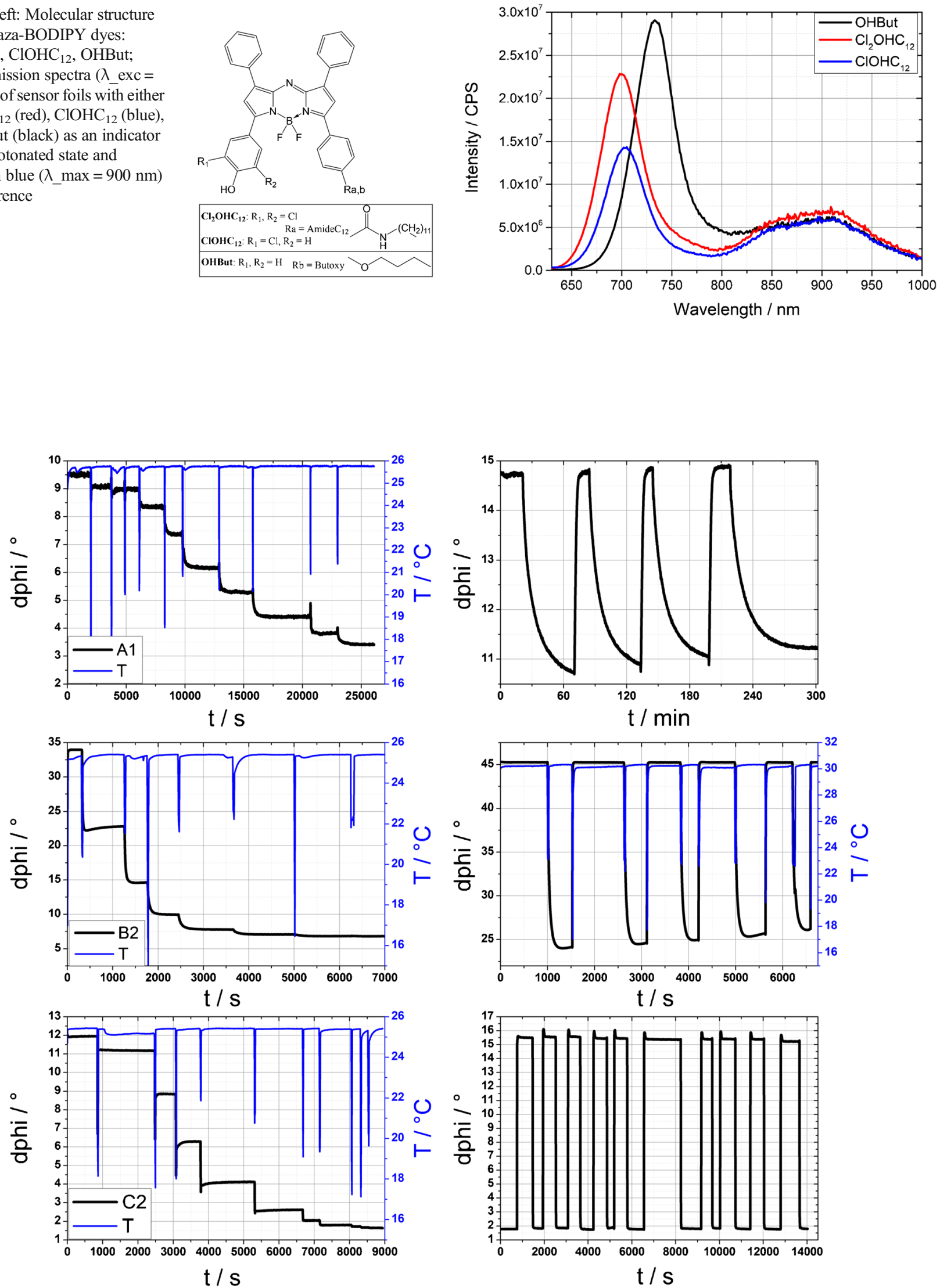

Fig. 4 Left: response curves of sensor A1, B2, and C2, the respective calibration concentrations can be seen in Fig. 5; right: hysteresis experiments of sensor A1 (10 $\mathrm{mg} \mathrm{L}^{-1} \mathrm{NH}_{3}$ vs 0 buffer), B2 (100 mg L $\mathrm{m}^{-1}$ vs $\left.10 \mathrm{mg} \mathrm{L}^{-1} \mathrm{NH}_{3}\right)$, and $\mathrm{C} 2\left(6 \mathrm{~g} \mathrm{~L}^{-1} \mathrm{NH}_{3}\right.$ vs 0 buffer) 


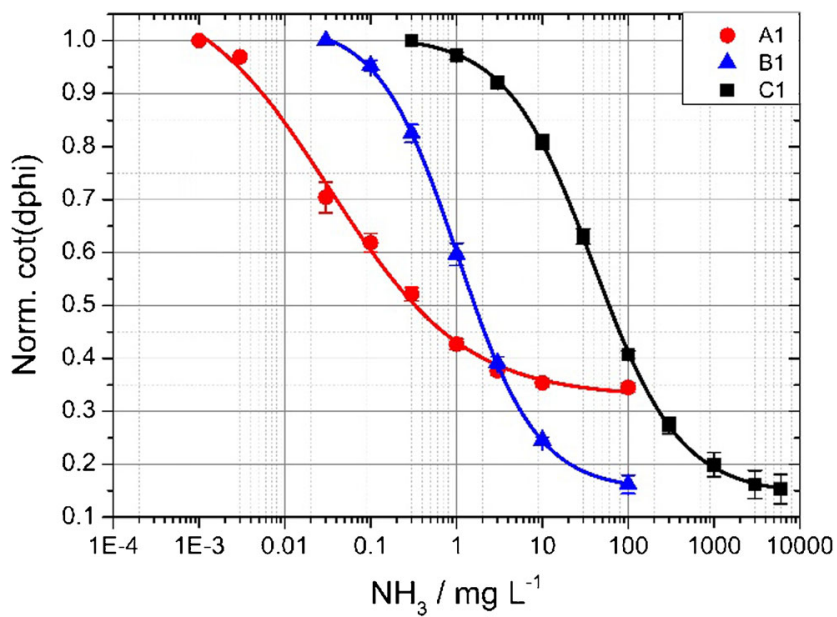

Fig. 5 Calibration curves of the three different ammonia sensors at $25^{\circ} \mathrm{C}$, using ion barrier porous Teflon membrane

$y=\mathrm{A} 2+\frac{\mathrm{A} 1-\mathrm{A} 2}{1+10^{\frac{\log (x)-x_{0}}{d x}}}$

Here, $y$ is the value of the normalized $\cot (\mathrm{dphi}), \mathrm{A} 1$ and A2 represent the upper and the lower plateau, $x$ represents the concentration of the calibration point, $x_{0}$ is the point of inflection, and $d x$ is the slope of the curve.

Figure 5 shows the calibration curves of three different sensors $(\mathrm{A} 1, \mathrm{~B} 1, \mathrm{C} 1)$. They vary in their indicator dye but all have the same ion barrier (see Table 1). A1 (red line) uses the dye with the lowest apparent $\mathrm{p} K_{\mathrm{a}}$ of 3.93 value, whereas $\mathrm{C} 1$ (black line) incorporates the dye with the highest apparent $\mathrm{p} K_{\mathrm{a}}$ of 8.90. To summarize, the lower the hydroxy groups $\mathrm{p} K_{\mathrm{a}}$ of the $\mathrm{pH}$ dye, the more sensitive the sensor. The flexible tuning of the dynamic range of the sensor offers a big variety in many different application fields. Since the crucial ammonia concentration for many living organism is $25 \mu \mathrm{g} \mathrm{L}^{-1}$, sensor type A (LOD of $0.23 \mu \mathrm{g} \mathrm{L}^{-1}$ ) has high potential for application in environmental monitoring [5]. Sensor type B (apparent $\mathrm{p} K_{\mathrm{a}}$ of 7.01, LOD of $28 \mu \mathrm{g} \mathrm{L}^{-1}$ ) has its dynamic range between approximately 1 and $100 \mathrm{mmol} \mathrm{L}^{-1} \mathrm{TAC}$ (total ammonia concentration, $\mathrm{NH}_{3}+\mathrm{NH}_{4}{ }^{+}$) which is suitable for monitoring biocatalytic reactions or fermentation processes [41-43]. Sensor type C (LOD of $0.51 \mathrm{mg} \mathrm{L}^{-1}$ ) can even measure higher concentrations of ammonia that can be interesting for industrial use or in flow chemistry for reaction monitoring. There, higher amounts of ammonia can be dissolved in water due to the high pressure in flow chemistry. The calculation of the LOD can be found in the ESM.

In the following section, one sensor type is always used to explain the results in detail. The trends in $\mathrm{pH}$, temperature influence, and response times for different protection layers are the same. We have tested three different ion barriers in this study. We wanted to investigate the influence of the ion barrier on the sensing properties of the various sensors.

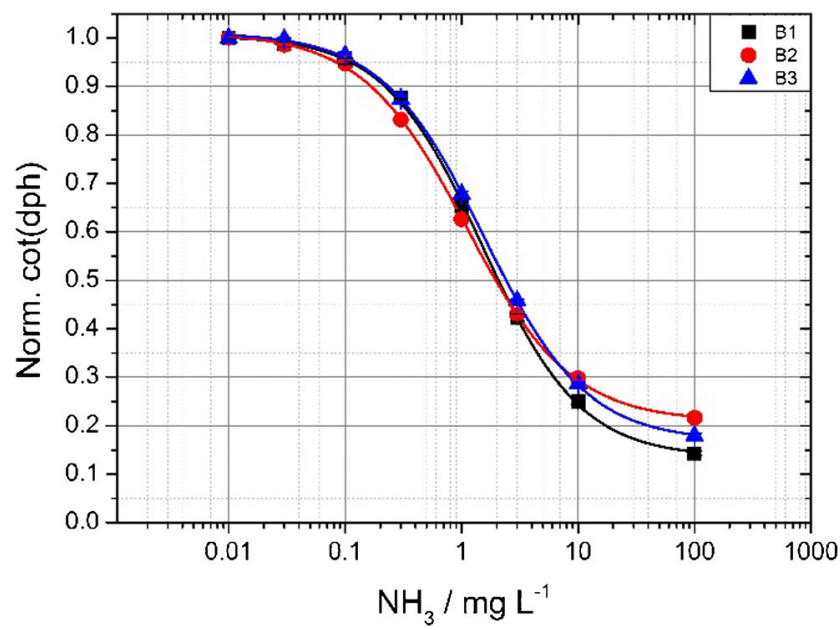

Fig. 6 Calibration curves of the three different ion barriers at $25^{\circ} \mathrm{C}$, using dye $\mathrm{ClOHC}_{12}$

Therefore, we calibrated sensors B1, B2, and B3 at the same time in the same buffer solutions. This experiment was performed for all sensor types and yields to the same trend in their results. Figure 6 shows that there are hardly any differences in lower concentration ranges. However, a small difference is detectable at higher concentrations. This might be attributed to inhomogeneities of the sensing layer that might be created within the emulsifying process. Nevertheless, in all three cases, the sensor works reversibly and with stability. Additionally, all three protection layers were tested against proton impermeability by dipping them into buffered solutions with different $\mathrm{pH}$ values (see ESM Figs. S5, S6, and S7). All three measurements show hardly any difference in the signals when changing the buffers, even though some of the $\mathrm{pH}$ buffers are far beyond the apparent $\mathrm{p} K_{\mathrm{a}}$ value of the used aza-BODIPY dye. This correlates with former studies $[36,39,44]$. Hysteresis experiments were performed for stability tests. The best results show sensor $\mathrm{C} 2$ (Fig. 4, right part). This sensor outperforms all others and shows barely any drift after 10 cycles - neither at very high free ammonia concentrations $\left(6 \mathrm{~g} \mathrm{~L}^{-1}\right)$ nor at 0 buffer. The sensor response is still fast and the signal stable after reaching the respective plateau. Other sensor types do show a less stable performance within this experiment. Especially when changing from very high ammonia concentrations to 0 buffer, their baseline signal rises over time. This can be explained with a slower mass transfer of ammonia between the hydrogel and the buffer solution. This effect is more pronounced in the trace measurements than at very high concentrations. Further information about the long-term stability of the sensors can be found in the ESM (Fig. S8).

The temperature dependency is shown in Fig. 7. For sensor type B, we estimated that temperatures between 25 and $45^{\circ} \mathrm{C}$ would be reasonable since this sensor is suitable for operations in biotechnology. Plotting the free ammonia concentration against the normalized $\cot (\mathrm{dphi})$ measured at different 

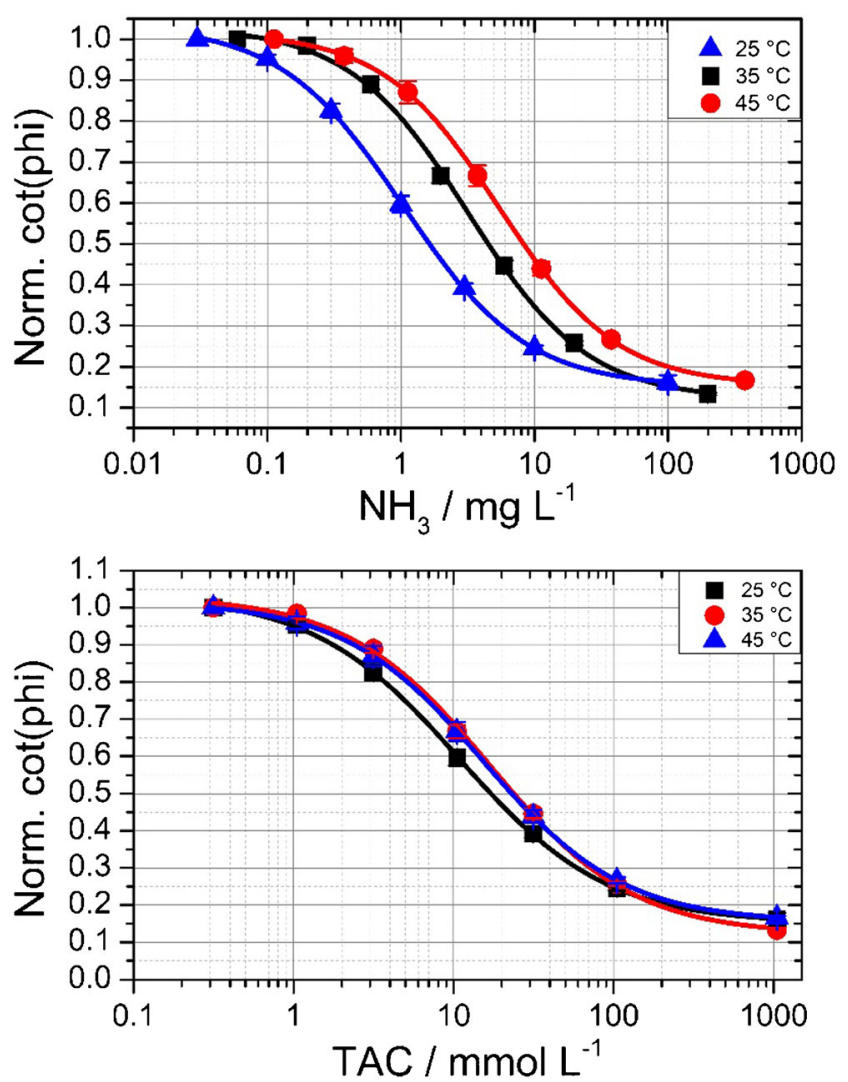

Fig. 7 Influence of temperature, sensor B1, upper part plotted vs free $\mathrm{NH}_{3}$ in $\mathrm{mg} \mathrm{L}^{-1}$, lower part plotted vs TAC in $\mathrm{mmol} \mathrm{L}^{-1}$

temperatures can yield to a wrong interpretation of the results. The upper graphic in Fig. 7 shows a shift of the calibration curve at different temperatures. When increasing the temperature, the sensor seems to get less sensitive but we have to consider that the ammonia ammonium equilibrium strongly depends on the temperature and the $\mathrm{pH}$ (see ESM Figs. S1 and S2). Based on this information, we only see the shift in free ammonia concentration of each buffer at different temperatures and not a different sensor behavior. For the correct evaluation of the data, plotting of normalized cot(dphi) against TAC is useful. The lower graphic in Fig. 7 shows three calibration curves of sensor B1 at 25,35 , and $45^{\circ} \mathrm{C}$. The temperature influence on the sensing properties of the sensor between 35 and $45^{\circ} \mathrm{C}$ is negligibly low, whereas at $25^{\circ} \mathrm{C}$ a small shift can be detected.

Besides different temperatures, the response time of the sensor system is basically limited to two main factors. The diffusion rate of ammonia through the PDMS matrix to the dye molecules, which are incorporated in the hydrogel, and the different ion barriers having an influence on the response time. Since the PDMS matrix is used in all three sensor types, we focus on the different protection layers. While the sensors of categories $\mathrm{A}, \mathrm{B}$, and $\mathrm{C}$ vary in their indicator dye and therefore in their dynamic range due to different $\mathrm{p} K_{\mathrm{a}}$ values, we compare response and recovery times $\left(t_{90}\right)$ within one category. As examples, sensors B1-B3 measured at $25{ }^{\circ} \mathrm{C}$ are used for comparing all three protection layers. Concerning their response as well as their recovery times, sensors B1 and B2 are similar. At the lowest calibration point $\left(0.01 \mathrm{mg} \mathrm{L}^{-1}\right), \mathrm{B} 1$ has a response time of $10 \mathrm{~min}$, whereas $\mathrm{B} 2$ is slightly faster with $9 \mathrm{~min}$. The recovery times behave similarly. In contrast to that, B3 is clearly slower than the other two $\left(t_{90}=55 \mathrm{~min}\right)$. The same trend can be seen at the highest calibration solution $\left(100 \mathrm{~m} \mathrm{~L} \mathrm{~L}^{-1}\right)$. There, $\mathrm{B} 1$ responds within $15 \mathrm{~s}$ and B2 in $25 \mathrm{~s}$, whereas B3 requires $390 \mathrm{~s}$. An overview of the response and recovery times of the other sensors is given in the ESM (Table S2).

\section{Conclusion}

To summarize, we were able to develop a variety of optical sensors for application in analytical ammonia determination. Therefore, we implemented the respective fluorescent and photostable aza-BODIPY dye in hydrogel D4 which is emulsified into a PDMS matrix. Varying $\mathrm{p} K_{\mathrm{a}}$ values of the dye's hydroxyl group yield to different dynamic ranges of the respective sensor making this system a powerful and flexible tool for ammonia determination in totally different fields. Possible applications range from environmental monitoring (fish farming; sensor type A) to biotechnological applications (bioreactor, biocatalysis; sensor type B) and even flow chemistry (reaction monitoring, sensor type C). Compared to our previous study published by Strobl in 2017 in this field, we decreased the response time of the trace sensor (type A, $10 \mathrm{mg} \mathrm{L}^{-1}-1 \mu \mathrm{g} \mathrm{L}^{-1}$ ) drastically and expanded the possible application fields by introducing two new sensor types (B and C). Thereby, sensor type B covers the concentration range of free dissolved ammonia from $100 \mathrm{mg} \mathrm{L}^{-1}$ down to $0.1 \mathrm{mg} \mathrm{L}^{-1}$ and type $\mathrm{C}$ is suitable for higher concentrations from $1 \mathrm{~g} \mathrm{~L}^{-1}$ to $1 \mathrm{mg} \mathrm{L}^{-1}$. The decrease in sensor response time can be attributed to matrix changes and the usage of different protection layers. Studying various ion barriers yield to significant differences in the response time of the sensor. Here, hydrophobic PES and the porous Teflon layer yield to comparable results and clearly outperform a knife-coated $\mathrm{PDMS} / \mathrm{TiO}_{2}$ layer. No significant influence of $\mathrm{pH}$ can be observed.

Acknowledgments The authors thank Martin Strobl and Anna Walcher for the dye synthesis and development, David Pfeifer (ACFC, Graz University of Technology) for the helpful discussions concerning emulsions, and Kevin Viebrock (Biotechnology, Technische Universität Braunschweig) for his help in the calibration measurements.

Funding information Open access funding provided by Graz University of Technology.

\section{Compliance with ethical standards}

Conflict of interest The authors declare that they have no conflict of interest. 
Open Access This article is licensed under a Creative Commons Attribution 4.0 International License, which permits use, sharing, adaptation, distribution and reproduction in any medium or format, as long as you give appropriate credit to the original author(s) and the source, provide a link to the Creative Commons licence, and indicate if changes were made. The images or other third party material in this article are included in the article's Creative Commons licence, unless indicated otherwise in a credit line to the material. If material is not included in the article's Creative Commons licence and your intended use is not permitted by statutory regulation or exceeds the permitted use, you will need to obtain permission directly from the copyright holder. To view a copy of this licence, visit http://creativecommons.org/licenses/by/4.0/.

\section{References}

1. Strömberg N, Hakonen A. Plasmophore sensitized imaging of ammonia release from biological tissues using optodes. Anal Chim Acta. 2011;704:139-45. https://doi.org/10.1016/j.aca.2011.08.019.

2. Ling Ling T, Ahmad M, Yook Heng L (2011) An amperometric biosensor based on alanine dehydrogenase for the determination of low level of ammonium ion in water. J Sens. https://www.hindawi. com/journals/js/2011/980709/. Accessed 21 Nov 2019.

3. Li QP, Zhang J-Z, Millero FJ, Hansell DA. Continuous colorimetric determination of trace ammonium in seawater with a long-path liquid waveguide capillary cell. Mar Chem. 2005;96:73-85. https://doi.org/10.1016/j.marchem.2004.12.001.

4. Lee DS, Atkins DHF. Atmospheric ammonia emissions from agricultural waste combustion. Geophys Res Lett. 1994;21:281-4. https://doi.org/10.1029/94GL00185.

5. Timmer B, Olthuis W, van den Berg A. Ammonia sensors and their applications - a review. Sens Actuators B: Chem. 2005;107:66677. https://doi.org/10.1016/j.snb.2004.11.054.

6. Randall DJ, Tsui TKN. Ammonia toxicity in fish. Mar Pollut Bull. 2002;45:17-23. https://doi.org/10.1016/S0025-326X(02)00227-8.

7. Irani N, Wirth M, van den Heuvel J, Wagner R. Improvement of the primary metabolism of cell cultures by introducing a new cytoplasmic pyruvate carboxylase reaction. Biotechnol Bioeng. 66:238-46. https://doi.org/10.1002/(SICI)1097-0290(1999)66:4<238::AIDBIT5>3.0.CO;2-6

8. Yuan Y, Jiang Y-C, Sun C-K, Chen Q-M. Role of the tumor microenvironment in tumor progression and the clinical applications (review). Oncol Rep. 2016;35:2499-515. https://doi.org/10.3892/ or.2016.4660.

9. Reitzer LJ, Wice BM, Kennell D. Evidence that glutamine, not sugar, is the major energy source for cultured HeLa cells. J Biol Chem. 1979;254:2669-76.

10. Newland M, Greenfield PF, Reid S. Hybridoma growth limitations: the roles of energy metabolism and ammonia production. Cytotechnology. 1990;3:215-29. https://doi.org/10.1007/ BF00365485.

11. Claps R, Englich FV, Leleux DP, Richter D, Tittel FK, Curl RF. Ammonia detection by use of near-infrared diode-laser-based overtone spectroscopy. Appl Opt, AO. 2001;40:4387-94. https://doi. org/10.1364/AO.40.004387.

12. Meyerhoff ME, Fraticelli YM, Greenberg JA, Rosen J, Parks SJ, Opdycke WN. Polymer-membrane electrode-based potentiometric sensing of ammonia and carbon dioxide in physiological fluids. Clin Chem. 1982;28:1973-8.

13. Crowley K, Morrin A, Hernandez A, O'Malley E, Whitten PG, Wallace GG, et al. Fabrication of an ammonia gas sensor using inkjet-printed polyaniline nanoparticles. Talanta. 2008;77:710-7. https://doi.org/10.1016/j.talanta.2008.07.022.
14. Schmohl A, Miklós A, Hess P. Detection of ammonia by photoacoustic spectroscopy with semiconductor lasers. Appl Opt, AO. 2002;41:1815-23. https://doi.org/10.1364/AO.41.001815.

15. Bozóki Z, Mohácsi Á, Szabó G, Bor Z, Erdélyi M, Chen W, et al. Near-infrared diode laser based spectroscopic detection of ammonia: a comparative study of photoacoustic and direct optical absorption methods. Appl Spectrosc. 2002. https://doi.org/10.1366/ 000370202760077658.

16. Owens MA, Davis CC, Dickerson RR. A photothermal interferometer for gas-phase ammonia detection. Anal Chem. 1999;71:13919. https://doi.org/10.1021/ac980810h.

17. Daridon A, Sequeira M, Pennarun-Thomas G, Dirac H, Krog JP, Gravesen P, et al. Chemical sensing using an integrated microfluidic system based on the Berthelot reaction. Sens Actuators B: Chem. 2001;76:235-43. https://doi.org/10.1016/ S0925-4005(01)00573-1.

18. Gordon SA, Fleck A, Bell J. Optimal conditions for the estimation of ammonium by the Berthelot reaction. Ann Clin Biochem. 1978;15:270-5. https://doi.org/10.1177/000456327801500164.

19. Krug FJ, Růžička J, Hansen EH. Determination of ammonia in low concentrations with Nessler's reagent by flow injection analysis. Analyst. 1979;104:47-54. https://doi.org/10.1039/ AN9790400047.

20. Preininger C, Mohr GJ, Klimant I, Wolfbeis OS. Ammonia fluorosensors based on reversible lactonization of polymerentrapped rhodamine dyes, and the effects of plasticizers. Anal Chim Acta. 1996;334:113-23. https://doi.org/10.1016/S00032670(96)00269-3.

21. Preininger C, Mohr GJ. Fluorosensors for ammonia using rhodamines immobilized in plasticized poly(vinyl chloride) and in solgel; a comparative study. Anal Chim Acta. 1997;342:207-13. https://doi.org/10.1016/S0003-2670(96)00607-1.

22. Waich K, Mayr T, Klimant I. Microsensors for detection of ammonia at ppb-concentration levels. Meas Sci Technol. 2007;18:3195. https://doi.org/10.1088/0957-0233/18/10/S22.

23. Lobnik A, Wolfbeis OS. Sol-gel based optical sensor for dissolved ammonia. Sens Actuators B: Chem. 1998;51:203-7. https://doi.org/ 10.1016/S0925-4005(98)00189-0.

24. Deng S, Doherty W, McAuliffe MA, Salaj-Kosla U, Lewis L, Huyet G. A low-cost, portable optical sensing system with wireless communication compatible of real-time and remote detection of dissolved ammonia. Photonic Sens. 2016;6:107-14. https://doi. org/10.1007/s13320-016-0291-2.

25. Mayr T, Borisov SM, Abel T, Enko B, Waich K, Mistlberger G, et al. Light harvesting as a simple and versatile way to enhance brightness of luminescent sensors. Anal Chem. 2009;81:6541-5. https://doi.org/10.1021/ac900662x.

26. Widmer S, Dorrestijn M, Camerlo A, Korent Urek Š, Lobnik A, Housecroft EC, et al. Coumarin meets fluorescein: a Förster resonance energy transfer enhanced optical ammonia gas sensor. Analyst. 2014;139:4335-42. https://doi.org/10.1039/ C4AN00061G.

27. Waich K, Borisov SM, Mayr T, Klimant I. Dual lifetime referenced trace ammonia sensors. Sens Actuators B: Chem. 2009;139:132-8. https://doi.org/10.1016/j.snb.2008.10.010.

28. Urriza-Arsuaga I, Bedoya M, Orellana G. Tailored luminescent sensing of NH3 in biomethane productions. Sens Actuators B: Chem. 2019;292:210-6. https://doi.org/10.1016/j.snb.2019.04. 109.

29. Mills A, Wild L, Chang Q. Plastic colorimetric film sensors for gaseous ammonia. Mikrochim Acta. 1995;121:225-36. https:// doi.org/10.1007/BF01248252.

30. Werner T, Klimant I, Wolfbeis OS. Ammonia-sensitive polymer matrix employing immobilized indicator ion pairs. Analyst. 1995;120:1627-31. https://doi.org/10.1039/AN9952001627. 
31. Jokic T, Borisov SM, Saf R, Nielsen DA, Kühl M, Klimant I. Highly photostable near-infrared fluorescent $\mathrm{pH}$ indicators and sensors based on BF2-chelated tetraarylazadipyrromethene dyes. Anal Chem. 2012;84:6723-30. https://doi.org/10.1021/ac3011796.

32. Lu H, Mack J, Yang Y, Shen Z. Structural modification strategies for the rational design of red/NIR region BODIPYs. Chem Soc Rev. 2014;43:4778-823. https://doi.org/10.1039/C4CS00030G.

33. Maierhofer M, Borisov SM, Mayr T. Optical ammonia sensor for continuous bioprocess monitoring. Proceedings. 2018;2:1041. https://doi.org/10.3390/proceedings2131041.

34. Strobl M, Rappitsch T, Borisov SM, Mayr T, Klimant I. NIRemitting aza-BODIPY dyes - new building blocks for broadrange optical pH sensors. Analyst. 2015;140:7150-3. https://doi. org/10.1039/C5AN01389E.

35. Borisov SM, Würth C, Resch-Genger U, Klimant I. New life of ancient pigments: application in high-performance optical sensing materials. Anal Chem. 2013;85:9371-7. https://doi.org/10.1021/ ac402275g.

36. Strobl M, Walcher A, Mayr T, Klimant I, Borisov SM. Trace Ammonia sensors based on fluorescent near-infrared-emitting aza-BODIPY dyes. Anal Chem. 2017;89:2859-65. https://doi.org/ 10.1021/acs.analchem.6b04045.

37. Klimant I, Huber C, Liebsch G, Neurauter G, Stangelmayer A, Wolfbeis OS. Dual lifetime referencing (DLR) - a new scheme for converting fluorescence intensity into a frequency-domain or time-domain information. In: Valeur B, Brochon J-C, editors. New trends in fluorescence spectroscopy: applications to chemical and life sciences. Berlin: Springer Berlin Heidelberg; 2001. p. 25774 .
38. Makhloufi C, Roizard D, Favre E. Reverse selective NH3/CO2 permeation in fluorinated polymers using membrane gas separation. J Membr Sci. 2013;441:63-72. https://doi.org/10.1016/j. memsci.2013.03.048.

39. Abel T, Ungerböck B, Klimant I, Mayr T. Fast responsive, optical trace level ammonia sensor for environmental monitoring. Chem Cent J. 2012;6:124. https://doi.org/10.1186/1752-153X-6-124.

40. Whelan A, Regan F. Antifouling strategies for marine and riverine sensors. J Environ Monit. 2006;8:880-6. https://doi.org/10.1039/ B603289C.

41. Rosini E, Caldinelli L, Piubelli L. Assays of D-amino acid oxidase activity. Front Mol Biosci. 2018;4. https://doi.org/10.3389/fmolb. 2017.00102

42. Pollegioni L, Molla G, Sacchi S, Rosini E, Verga R, Pilone MS. Properties and applications of microbial D-amino acid oxidases: current state and perspectives. Appl Microbiol Biotechnol. 2008;78:1-16. https://doi.org/10.1007/s00253-007-1282-4.

43. Batool T, Makky EA, Jalal M, Yusoff MM. A comprehensive review on 1-asparaginase and its applications. Appl Biochem Biotechnol. 2016;178:900-23. https://doi.org/10.1007/s12010015-1917-3

44. Müller BJ, Steinmann N, Borisov SM, Klimant I. Ammonia sensing with fluoroionophores - a promising way to minimize interferences caused by volatile amines. Sens Actuators B: Chem. 2017. https://doi.org/10.1016/j.snb.2017.08.209.

Publisher's note Springer Nature remains neutral with regard to jurisdictional claims in published maps and institutional affiliations. 